\title{
Covalent Organic Framework Constructed by Clicking Azido Porphyrin with Perpropargyloxy-Cucurbit[6]uril for Electrocatalytic Hydrogen Generation from Water Splitting
}

\author{
Aisan Khaligh, Yasaman Sheidaei, and Dönüs Tuncel* \\ Cite This: ACS Appl. Energy Mater. 2021, 4, 3535-3543 \\ Read Online
}

ACCESS | Llll Metrics \& More | 国 Article Recommendations | sl Supporting Information

ABSTRACT: In the present study, we describe the synthesis and characterization of a new covalent organic framework (COF-TPP-CB[6]) which was assembled together by clicking perpropargyloxy cucurbit[6]uril $(\mathbf{C B}[6])$ to the azidofunctionalized tetraphenylporphyrin $\left(\mathrm{TPP}-4 \mathrm{~N}_{3}\right)$ through a copper-catalyzed azide-alkyne cycloaddition reaction (CuAAC). Perpropargyloxy $\mathrm{CB}[6]$ was synthesized through the direct oxidation of $\mathbf{C B}[6]$ to afford perhydroxy $\mathbf{C B}[6]$ followed by subsequent $\mathrm{O}$-propargylation using $\mathrm{NaH}$. We also demonstrated that the resulting framework (COF-TPP-CB[6]) can be employed as an efficient and stable electrocatalyst for hydrogen evolution reaction (HER) in alkaline medium upon loading it with a nickel cocatalyst. The effect of $\mathrm{TiO}_{2}$ and different loadings of $\mathrm{Ni}$ on the HER performance of TPP-CB[6] was also studied. Herein, 12\%Ni@ TPP-CB $[6]$ as the optimum catalyst showed an impressive $\mathrm{H}_{2}$ production rate of $18.7 \mathrm{mmol} \mathrm{h}^{-1} \mathrm{~g}^{-1}$ with a low onset potential of $-250 \mathrm{mV}$.

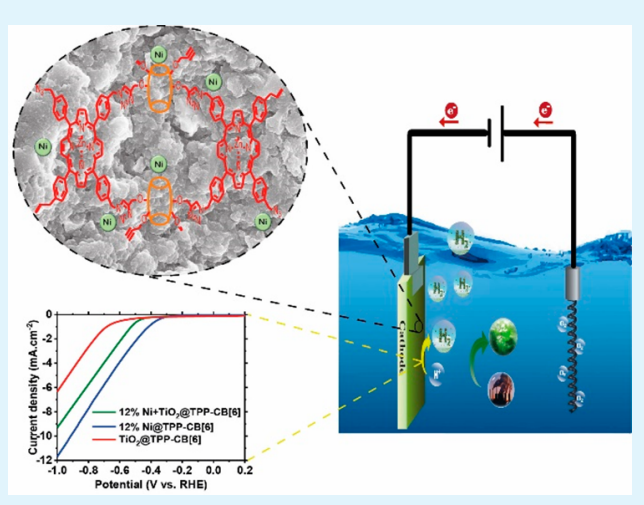

KEYWORDS: covalent organic framework, perpropargyloxy cucurbit[6] uril, porphyrin, click reaction, electrocatalytic hydrogen production, water splitting, nickel

\section{INTRODUCTION}

Multifunctional supramolecular assemblies have emerged as promising candidates for a wide range of applications owing to their well-designed structures and outstanding properties. ${ }^{1-3}$ Porphyrins are highly attractive building blocks used in the construction of supramolecular assemblies due to their rigidity, planar structure, ease of chemical modification, and chemical flexibility and stability. Thanks to their large $\pi$-conjugated aromatic domain, porphyrins exhibit remarkable photophysical and electrochemical properties. ${ }^{4-7}$ Furthermore, their superior structural properties facilitate the attachment of various functionalities to their large hydrophobic cores, thereby providing multifunctional assemblies with diverse functionalities and potential applications in biomedicine, electro/photo catalysis, molecular electronics, artificial light harvesting, sensing, and so forth. ${ }^{4-16}$

Porphyrins can be covalently or noncovalently modified. ${ }^{17}$ Cucurbit $[n]$ urils, $\mathbf{C B}[n] \mathrm{s}(n=5-10)$, are robust macrocyclic structures that are formed from supramolecular assemblies with porphyrins mainly through noncovalent interactions, ${ }^{2,18-26}$ in which functionalized $\mathbf{C B}[n] \mathrm{s}$ do not attach directly to the porphyrin core. $\mathbf{C B}[n] \mathrm{s}$ composed of $n$ glycoluril units linked by methylene bridges. They are composed of two partially negatively charged hydrophilic carbonyl rims and a hydrophobic cavity. Outstanding features such as rigid structure, high chemical stability, low toxicity, high guest binding affinity, and size selectivity enable $\mathbf{C B}[n]$ s to act as interesting synthetic receptors and building blocks for supramolecular assemblies. ${ }^{2,27,28}$ Synthesis of functionalized $\mathbf{C B}[n]$ s derivatives is of crucial importance as it can facilitate the design of various supramolecular assemblies with developed applications. ${ }^{29}$ There are two main ways to introduce functional groups on $\mathbf{C B}[n] \mathrm{s}$ : the use of functionalized precursors ${ }^{29}$ and postfunctionalization. ${ }^{30,31}$ The latter approach seems to be more practical as it allows the modification of $\mathrm{CB}[n] \mathrm{s}$ in moderate yields. Unfortunately, direct functionalization of $\mathbf{C B}[n] \mathrm{s}$ is still a challenging aspect because of their high stability. ${ }^{31}$ Hence, studies on the synthesis and application of functionalized $\mathbf{C B}[n] \mathrm{s}$ in nanostructures are still limited. ${ }^{28,32,33}$ Accordingly, examples on covalently linked $\mathbf{C B}[n]$-porphyrin assemblies are quite rare. One of the first studies on the covalent porphyrin-CB $[n]$ multifunctional supramolecular assemblies was reported by our group in 2018 by conjugation of monopropargyloxy-CB [7] to a triglycosylated-porphyrin (TPP) core via copper-catalyzed azide-alkyne cycloaddition (Cu-AAC) reaction. ${ }^{34}$ The pre-

Received: December 30, 2020

Accepted: March 10, 2021

Published: March 18, 2021 
pared conjugate was then employed in photodynamic antibacterial and cancer therapy. ${ }^{35}$ Another $\mathbf{C B}[n]$-porphyrin conjugation was then reported by our group in 2019 in which the monohydroxyl-CB[7] was conjugated to $4(\mathrm{TEG}-\mathrm{OH})$ TPP core. The as-prepared assembly was employed for electrophotocatalytic hydrogen generation from water splitting as well as photodynamic antibacterial and cancer therapy. ${ }^{36,37}$ In the present paper, we report a $\mathrm{CB}[6]$ and porphyrin-based covalent organic framework. We first synthesized $\mathbf{C B 6}(\mathbf{O}-\mathbf{P})_{n}$ by direct functionalization of $\mathrm{CB}[6]$ and then it was covalently attached to porphyrin core (TPP-Zn-4N $\mathbf{N}_{3}$ ) through $\mathrm{Cu}-\mathrm{AAC}$ click reaction to construct TPP-CB[6] covalent organic framework.

Electrocatalytic water splitting for efficient production of high purity hydrogen (and oxygen) is widely regarded as a promising process to transform and store renewable energy. ${ }^{38-40}$ Recently, growing interest in porphyrin-based hydrogen generation catalysts has been received due to their considerable synthetic flexibility, redox behavior, chemical stability, and tunable optoelectronic properties. Accordingly, the fabrication and development of new porphyrin-based electrocatalysts to promote the hydrogen evolution reaction (HER) to produce hydrogen from water splitting is of great importance. $^{41-43}$ In this regard, the electrocatalytic properties of the newly developed COF-TPP-CB [6] has been investigated in the electrocatalytic hydrogen generation from water splitting. Moreover, this framework is able to accommodate $\mathrm{Ni}$ ions as a cocatalyst because of the presence of various binding sites including carbonyl portals of CBs and triazole units for $\mathrm{Ni}$ ions to coordinate with.

\section{EXPERIMENTAL SECTION}

2.1. Chemicals. Propargyl bromide, sodium hydride, sodium azide, pyrrole, glycoluril, potassium persulfate, sodium hydride, zinc acetate, dimethyl sulfoxide, diethyl ether, chloroform, methanol, and all the other chemicals and reagents used for organic syntheses were of analytical grade and obtained from Sigma-Aldrich, unless otherwise stated. The deuterated solvent DMSO-d6 used in NMR was purchased from Merck. Nickel acetate tetra hydrate, titanium dioxide $\left(\mathrm{TiO}_{2}\right)$, potassium hydroxide, platinum on carbon $(\mathrm{Pt} / \mathrm{C})$, phosphatebuffered saline (PBS), and sulfuric acid $95-98 \%$ used in electrochemical experiments were obtained from Sigma-Aldrich. Nafion (5\% $\mathrm{w} / \mathrm{w}$ in water and 1-propanol, Alfa Aesar) was used as a binder during the preparation of electrode. Ultrapure deionized water $(R \geq 18 \mathrm{M} \Omega$ $\mathrm{cm}^{-1}$ ) from a Milli-Q plus water purification system (Millipore, Bedford, MA, U.S.A.) was used throughout the study.

2.2. Material Characterization. ${ }^{1} \mathrm{H}$ NMR spectra were obtained at $400 \mathrm{MHz}$, using Bruker Avance III $400 \mathrm{MHz}$ NMR spectrometer. Mass spectra were carried out using Agilent 6210 LC/MS TOF mass spectrometer. Scanning electron microscopy (SEM) imaging and energy dispersive X-ray (EDX) analysis were carried out using FEI Technai G2 F30 SEM. Transmission electron microscopy (TEM) imaging was done by FEI Tecnai $\mathrm{G}^{2}$ Spirit BioTwin CTEM (Central Laboratory, Middle East Technical University, Ankara, Turkey). A gas adsorption analyzer (Quantachrome autosorb iQ) was used to measure the Brunauer-Emmett-Teller (BET) surface area from nitrogen adsorption-desorption isotherms. Prior to the analysis the samples were degassed in vacuum at $90{ }^{\circ} \mathrm{C}$ for $2 \mathrm{~h}$. Fourier transform infrared spectroscopy (FT-IR) was recorded on a Bruker Alpha-II Platinum ATR FT-IR spectrometer. Optical absorption spectra were recorded with Cary 300 UV-vis spectrophotometer. X-ray diffraction patterns were recorded by the X-ray diffractometer (XRD, X'pert pro MPD, PANalytical Empyrean) equipped with a $\mathrm{Cu} \mathrm{K} \alpha$ irradiation source. $(40 \mathrm{kV}, 45 \mathrm{~mA}, \lambda=1.5405 \AA$ ). Chemical and elemental analyses were determined using X-ray photoelectron spectroscopy (XPS) (Thermo Fisher Scientific). Measurements were performed with a spot size of $\sim 400 \mu \mathrm{m}, 30 \mathrm{eV}$ pass energy, and $0.1 \mathrm{eV}$ step size. Thermal stability of the compound was studied using TA Instruments Q500 thermogravimetric analyzer.

2.3. Synthesis and Characterization of Precursors. $5,10,15,20$-Tetrakis $(\alpha$-bromo- $p$-tolyl)porphyrin (TPP-4Br), $5,10,15,20$-tetrakis $\left(\alpha\right.$-azido- $p$-tolyl) porphyrin $\left(\mathbf{T P P}-4 \mathbf{N}_{3}\right)$, azidofunctionalized metalated-porphyrin (TPP-Zn- $4 N_{3}$ ), and $\mathrm{CB}[6]$ were synthesized according to the literature procedures. ${ }^{34,44,45}$

2.3.1. Synthesis of Perhydroxy-CB[6], $\mathrm{CB} 6(\mathrm{OH})_{n}$. $\mathrm{CB} 6(\mathrm{OH})_{n}$ was synthesized according to the literature procedure. ${ }^{30} \mathrm{~A}$ slurry mixture of $\mathbf{C B}[6](1.00 \mathrm{~g}, 1.00 \mathrm{mmol})$ and $\mathrm{K}_{2} \mathrm{~S}_{2} \mathrm{O}_{8}(3.90 \mathrm{~g}, 14.4 \mathrm{mmol})$ in 50 $\mathrm{mL}$ degassed, dionized water was refluxed at $85{ }^{\circ} \mathrm{C}$ for $6 \mathrm{~h}$ under nitrogen atmosphere. The reaction mixture was then cooled down to room temperature and filtered. The precipitate was removed and the filtrate was concentrated to $25 \mathrm{~mL}$ under reduced pressure. Acetone vapor diffusion into the resulting solution gave a white precipitation, which was collected by filtration, washed with acetone, and dried in vacuum oven to give $\mathbf{C B 6}(\mathrm{OH})_{n}$ as a white solid. Yield: $950 \mathrm{mg}, 62 \%$.

ESI-MS $(m / z)$ : calcd for $\mathrm{C}_{36} \mathrm{H}_{36} \mathrm{O}_{24} \mathrm{~N}_{24} \mathrm{Na}[\mathrm{M} 12+\mathrm{Na}]^{+}$: 1211.2233, found: 1211.2002; calcd. for $\mathrm{C}_{36} \mathrm{H}_{36} \mathrm{O}_{24} \mathrm{~N}_{24} \mathrm{~K}$ $[\mathrm{M} 12+\mathrm{K}]^{+}$: 1227.19727 , found: 1227.1999; calcd. for $\mathrm{C}_{36} \mathrm{H}_{36} \mathrm{O}_{23} \mathrm{~N}_{24} \mathrm{~K}[\mathrm{M} 11+\mathrm{K}]^{+}$: 1211.20235, found: 1211.2002; calcd. for $\mathrm{C}_{36} \mathrm{H}_{36} \mathrm{O}_{24} \mathrm{~N}_{24} \mathrm{Na}_{2}$ [M12 $\left.+2 \mathrm{Na}\right]^{+}: 617$, found: 617.0893; calcd. for $\mathrm{C}_{36} \mathrm{H}_{36} \mathrm{O}_{24} \mathrm{~N}_{24} \mathrm{KNa}$ [M12+NaK] $]^{+}: 625.0935$, found: 625.0839; calcd. For $\mathrm{C}_{36} \mathrm{H}_{36} \mathrm{O}_{24} \mathrm{~N}_{24} \mathrm{~K}_{2}[\mathrm{M} 12+2 \mathrm{~K}]^{2+}$ : 633.0804, found: 633.0814; calcd. for $\mathrm{C}_{36} \mathrm{H}_{36} \mathrm{O}_{23} \mathrm{~N}_{24} \mathrm{Na}_{2}[\mathrm{M} 11+2 \mathrm{Na}]^{2+}: 609.1091$, found: 609.0897; calcd. for $\mathrm{C}_{36} \mathrm{H}_{36} \mathrm{O}_{23} \mathrm{~N}_{24} \mathrm{~K}_{2}[\mathrm{M} 11+2 \mathrm{~K}]^{2+}$ : 625.0830, Ffound: 625.0839; calcd. for $\mathrm{C}_{36} \mathrm{H}_{36} \mathrm{O}_{22} \mathrm{~N}_{24} \mathrm{Na}_{2}[\mathrm{M} 10+2 \mathrm{Na}]^{2+}$ : 601.1116, found: 601.0867; where $\mathrm{M}$ is $\mathrm{CB6}(\mathrm{OH})$ and $n$ is the number of hydroxy groups, $\mathrm{M}_{n} \approx \mathrm{CB} 6(\mathrm{OH})_{n}$

2.3.2. Synthesis of Perpropargyloxy-CB[6] $\left(C B 6(O-P)_{n}\right)$. CB6(O$\mathbf{P})_{n}$ was synthesized modifying the literature procedure. ${ }^{30}$ To a stirred solution of $\mathrm{CB} 6(\mathrm{OH})_{n}(500 \mathrm{mg}, 0.42 \mathrm{mmol})$ in $12 \mathrm{~mL}$ dry DMSO, $\mathrm{NaH}$ (239 mg, $9.98 \mathrm{mmol}$ ) was added at room temperature (RT) and under an inert nitrogen atmosphere. After $3 \mathrm{~h}$ stirring at RT, propargyl bromide $(0.9 \mathrm{~mL}, 10 \mathrm{mmol})$ was added into the reaction flask. The reaction mixture was stirred at RT overnight, followed by adding $3 \mathrm{~mL}$ methanol at $0{ }^{\circ} \mathrm{C}$. The flask content was then poured into $200 \mathrm{~mL}$ diethyl ether, brownish solid was precipitated out, collected by filtration, and washed several times with water and diethyl ether. The product was finally oven-dried at $50{ }^{\circ} \mathrm{C}$ to give CB6 $(\mathrm{O}-\mathrm{P})_{n}$ as a brownish solid. Yield: $368 \mathrm{mg}, 65 \%$.

ESI-MS $(m / z)$ : calcd for $\mathrm{C}_{51} \mathrm{H}_{46} \mathrm{O}_{22} \mathrm{~N}_{24} \mathrm{Na}[\mathrm{M} 10 \mathrm{P} 5+\mathrm{Na}]^{+}$: 1369.3117, found: 1369.2739; calcd. for $\mathrm{C}_{51} \mathrm{H}_{46} \mathrm{O}_{23} \mathrm{~N}_{24} \mathrm{Na}$ $[\mathrm{M} 11 \mathrm{P} 5+\mathrm{Na}]^{+}:$1385.3066, found: 1385.2709; calcd. for $\mathrm{C}_{57} \mathrm{H}_{50} \mathrm{O}_{24} \mathrm{~N}_{24} \mathrm{~K}[\mathrm{M} 12 \mathrm{P} 7+2 \mathrm{Na}]^{+}: 1493.3068$, found: 1493.2590; calcd. for $\mathrm{C}_{42} \mathrm{H}_{40} \mathrm{O}_{16} \mathrm{~N}_{24} \mathrm{Na}_{2}[\mathrm{M} 4 \mathrm{P} 2+2 \mathrm{Na}]^{2+}: 591.1425$, found: 591.1477; calcd. for $\mathrm{C}_{39} \mathrm{H}_{38} \mathrm{O}_{22} \mathrm{~N}_{24} \mathrm{Cl}_{3}[\mathrm{M} 10 \mathrm{P} 1+3 \mathrm{Cl}]^{3+}: 433.055$, found: 433.2274; calcd. for $\mathrm{C}_{39} \mathrm{H}_{38} \mathrm{O}_{22} \mathrm{~N}_{24} \mathrm{H}_{3}[\mathrm{M} 10 \mathrm{P} 1+3 \mathrm{H}]^{3+}$ : 399.1943, found: 399.2046; where $\mathrm{M}_{n}$ is $\mathbf{C B 6}(\mathbf{O H})_{n}$ and $\mathrm{P}_{m}$ is the number of propargyloxy groups, $\mathrm{M}_{n} \mathrm{P}_{m} \approx \mathrm{CB} 6(\mathrm{OH})_{n}$ (O-propargyl $)_{m}$.

2.4. Synthesis of COF-TPP-CB[6]. CB6(O-P) ${ }_{n}(129 \mathrm{mg}, 0.089$ $\mathrm{mmol})$ and TPP-Zn-4N 3 (80 mg, $0.09 \mathrm{mmol})$ were separately dissolved in $2 \mathrm{~mL} \mathrm{DMSO}$ and then the solutions were mixed together. The mixture was stirred at $120{ }^{\circ} \mathrm{C}$ for $30 \mathrm{~min}$. A solution of copper sulfate $(2.0 \mathrm{mg}, 0.013 \mathrm{mmol})$ and sodium ascorbate $(4.0 \mathrm{mg}, 0.020$ $\mathrm{mmol}$ ) in $1 \mathrm{~mL}$ water was then added into the well stirred solution of reaction monomers. The reaction mixture was stirred at $120^{\circ} \mathrm{C}$ for 96 h. The progress of the reaction was monitored using FT-IR. After the completion of reaction (by disappearing of the azide band), the flask content was suspended in $20 \mathrm{~mL}$ water, brownish solid was precipitated out, filtered, washed several times with water and chloroform to remove the catalyst and excess precursors, and dried in vacuum oven at $50{ }^{\circ} \mathrm{C}$ to afford COF-TPP-CB $[6]$ as a brownish powder. Yield: $150 \mathrm{mg}$.

2.5. Electrochemical Measurements. Electrochemical experiments were performed using a $\mathrm{CHI}-670$ potentiostat $(\mathrm{CH}$ Instruments, China) at room temperature in a three-electrode cell configuration with $\mathrm{Ag} / \mathrm{AgCl} / \mathrm{KCl}_{(\text {sat. }}$, Pt wire, and ink coated fluorine tine oxide (FTO) as the reference, counter and working electrodes, 
Scheme 1. Synthesis of COF-TPP-CB [6]: (i) $\mathrm{K}_{2} \mathrm{~S}_{2} \mathrm{O}_{8}, \mathrm{H}_{2} \mathrm{O}, 85^{\circ} \mathrm{C}, 6 \mathrm{~h}, \mathrm{~N}_{2}$; (ii) NaH, Dry DMSO, Propargyl Bromide, $25{ }^{\circ} \mathrm{C}$, Overnight, $\mathrm{N}_{2}$; and (iii) DMSO, Copper Sulfate/Sodium Ascorbate, $120{ }^{\circ} \mathrm{C}, 96 \mathrm{~h}$
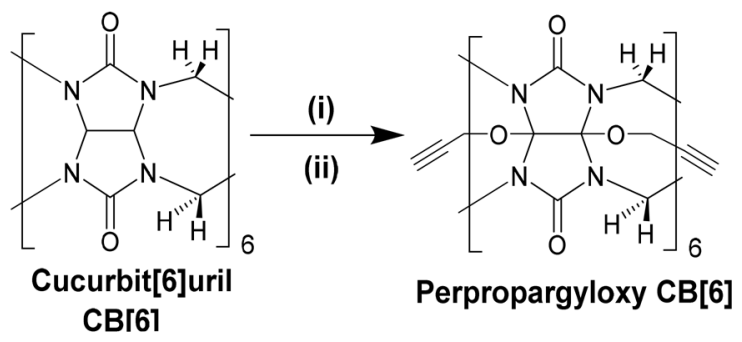

Perpropargyloxy CB[6]

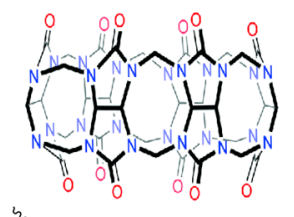

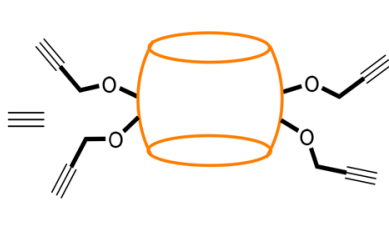

(iii)

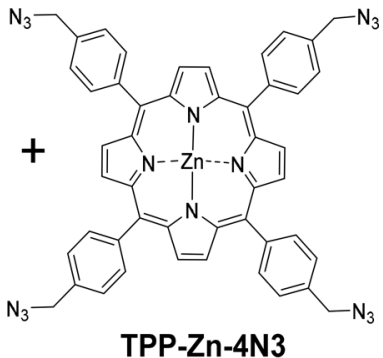

TPP-Zn-4N3

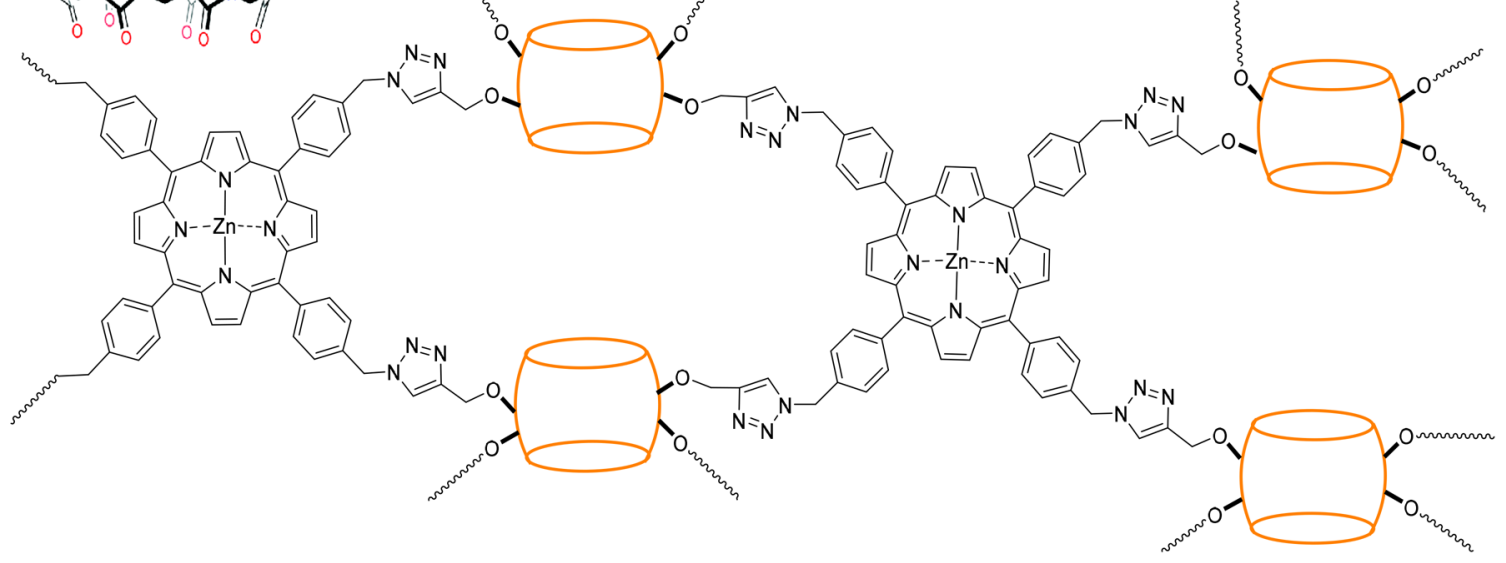

COF-TPP-CB[6]

respectively. The electrochemical experiments were measured in a 0.1 $\mathrm{M} \mathrm{KOH}$ electrolyte. Prior to each experiment, electrolyte was deaerated with Ar gas (99.999\% of purity) for $30 \mathrm{~min}$. Strips of $10 \times$ $20 \mathrm{~mm}^{2}$ of $2 \mathrm{~mm}$ thick FTO glass were cut from a sheet obtained from Sigma-Aldrich and before the electrode coating, FTO substrates were cleaned using water and detergent, followed by sequential sonication in water and isopropanol for $15 \mathrm{~min}$ and dried in air. FTO surface was then activated at $450{ }^{\circ} \mathrm{C}$ for $2 \mathrm{~h}$.

\section{RESULTS AND DISCUSSION}

\subsection{Synthesis and Characterization of COF-TPP-} CB[6]. The synthetic route to obtain the target TPP-CB6 covalent organic framework is provided in Scheme 1. This procedure involves the copper-catalyzed azide-alkyne cycloaddition (Cu-AAC) of TPP-Zn-4N $\mathbf{N}_{3}$ and $\mathbf{C B} 6(\mathrm{O}-\mathbf{P})_{n}$ as reaction monomers to form polytriazoles. $\mathrm{CB}[6]$, CB6(O$\mathbf{H})_{n}$, TPP-4Br, TPP-4N $\mathbf{N}_{3}$, and TPP-Zn- $\mathbf{4} \mathbf{N}_{3}$ were synthesized according to the previously reported procedures. ${ }^{30,34,44,45}$ Treatment of $\mathbf{C B 6}(\mathrm{OH})_{n}$ with excess sodium hydride in DMSO followed by its reaction with propargyl bromide afforded $\mathrm{CB} 6(\mathrm{O}-\mathrm{P})_{n}$. Both $\mathrm{CB}[6]$ derivatives were characterized by ${ }^{1} \mathrm{H}$ NMR, FT-IR, and ESI-mass spectroscopic techniques (Figures S1-S6 of the Supporting Information, SI). The appearance of alkyne stretching signals at $2158 \mathrm{~cm}^{-1}(\mathrm{C} \equiv$ C) and $3258 \mathrm{~cm}^{-1}(-\mathrm{C} \equiv \mathrm{C}-\mathrm{H})$ in the $\mathrm{FT}-\mathrm{IR}$ spectrum of the $\mathrm{CB6}(\mathrm{O}-\mathrm{P})_{n}$ (Figure S6a) compared to $\mathrm{CB6}(\mathrm{OH})_{n}$ (Figure S6b) further confirmed the success of the propargylation reaction (Figure S3). Azidation of TPP-4Br with excess sodium azide offorded TPP-4N 3 in $93 \%$ yield. ${ }^{34}$ Before proceeding with the (Cu-AAC) reaction, the core of TPP$\mathbf{4 N}_{3}$ was metalated with $\mathrm{Zn}$ to prevent inclusion of $\mathrm{Cu}$, which will decrease its catalytic effect. The metalation procedure was simply performed by refluxing of TPP- $4 \mathbf{N}_{3}$ with zinc acetate in methanol to obtain $\mathrm{Zn}(\mathrm{II})$-porphyrin. ${ }^{34}$ The synthesized porphyrin derivatives were fully characterized by ${ }^{1} \mathrm{H}$ NMR, FT-IR, ESI-mass and UV-vis spectroscopic techniques (Figures S7-S14).

Having the monomers prepared, here comes the final step to get the target covalently attached TPP-CB $[6]$ organic framework. To do so, a simple $\mathrm{Cu}-\mathrm{AAC}$ reaction was applied between $\mathbf{C B} 6(\mathbf{O}-\mathbf{P})_{n}$ (1 equiv) and TPP-Zn-4N $\mathbf{N}_{3}$ ( 1 equiv) in DMSO solvent at $120{ }^{\circ} \mathrm{C}$. The progress of the reaction was monitored by FT-IR to make sure the azide groups of the porphyrin reacted with the alkyne groups of propargyloxy functionalities of $\mathrm{CB}[6]$ via $\mathrm{AAC}$ reaction.

The as-synthesized COF-TPP-CB[6] was insoluble in water and organic solvents due to the 3D network structure, and it was fully characterized with ${ }^{1} \mathrm{H}$ NMR, FT-IR, XPS, SEM, EDX, BET, TGA, and XRD analyses. Although COF-TPP$\mathbf{C B}[6]$ is insoluble in any solvent, we managed to disperse it in DMSO-d6 after overnight stirring at room temperature and recorded its ${ }^{1} \mathrm{H}$ NMR spectrum (Figure S15). The ${ }^{1} \mathrm{H}$ NMR spectrum clearly shows the characteristic signals for the protons of CB6, porphyrin, and phenyl units. Figure 1 compares the FT-IR spectra of the COF-TPP-CB[6] with its monomers, TPP-Zn-4N 3 and perpropargyloxy-CB $[6]$. The appearance of the carbonyl signal at $1735 \mathrm{~cm}^{-1}$ and the decrease in the intensity of the azide and alkyne signals at 2095 and $3258 \mathrm{~cm}^{-1}$, respectively, in the FT-IR spectrum of the developed COF-TPP-CB[6] compared to TPP-Zn-4N $\mathbf{N}_{3}$ and CB6 $(\mathrm{O}-\mathrm{P})_{n}$ monomers, confirmed the success of $\mathrm{Cu}-\mathrm{AAC}$ 


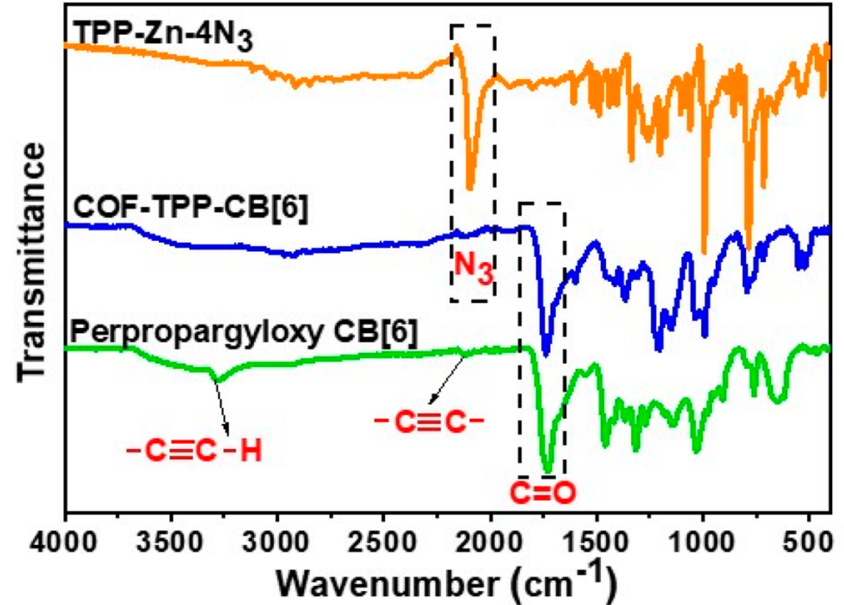

Figure 1. FT-IR spectra of COF-TPP-CB [6] compared to its monomers, TPP-Zn-4N $\mathrm{N}_{3}$ and $\mathrm{CB} 6(\mathrm{O}-\mathrm{P})_{n}$.

reaction. The chemical composition of the COF-TPP-CB[6] was further investigated using XPS. The C 1s XPS spectrum (Figure 2a) was fitted into six components 284.25, 284.85,
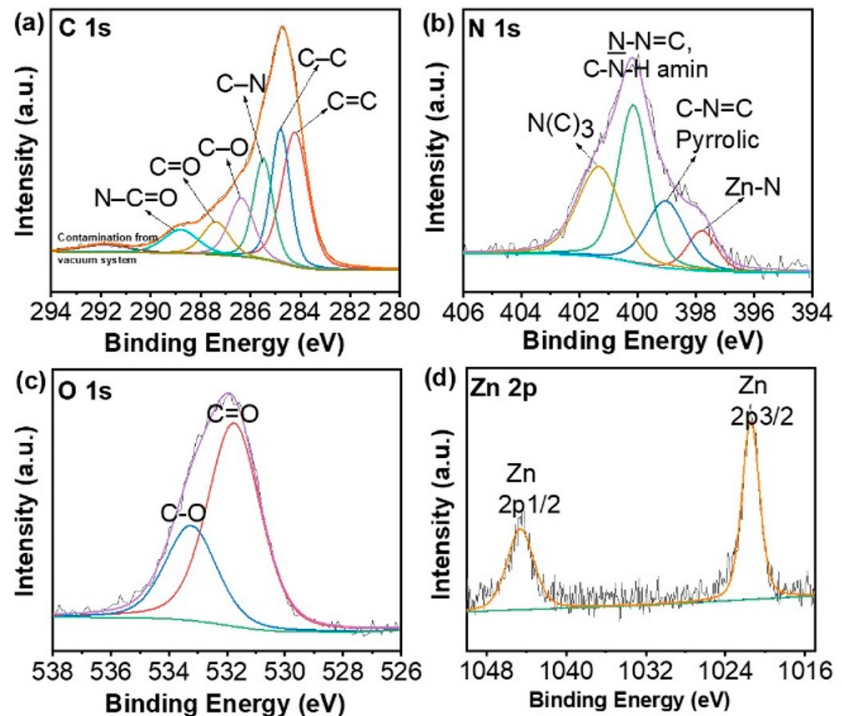

Figure 2. High resolution XPS spectra of (a) C 1s, (b) N 1s, (c) O 1s, and (d) Zn 2p regions for COF-TPP-CB[6].
$285.49,286.40,287.45$, and 288.90 corresponding to the $\mathrm{C}=$ $\mathrm{C}, \mathrm{C}-\mathrm{C}, \mathrm{C}-\mathrm{N}, \mathrm{C}-\mathrm{O}, \mathrm{C}=\mathrm{O}$, and $\mathrm{N}-\mathrm{C}=\mathrm{O}$ bonds, respectively. The XPS signal for $\mathrm{N} 1 \mathrm{~s}$ (Figure $2 \mathrm{~b}$ ) was fitted into four components at $397.75 \mathrm{eV}$ for $\mathrm{Zn}-\mathrm{N}, 399.04 \mathrm{eV}$ for pyrrolic-N, $400.17 \mathrm{eV}$ for triazole- $\mathrm{N}$ and amine-N, and 401.35 $\mathrm{eV}$ for graphitic-N. The $\mathrm{O} 1 \mathrm{~s}$ core level peak can be resolved into two components (Figure 2c) centered at 531.75 and $533.26 \mathrm{eV}$ corresponding to the $\mathrm{C}-\mathrm{O}$ and $\mathrm{C}=\mathrm{O}$ bonds, respectively. The high-resolution spectrum in the $\mathrm{Zn} 2 \mathrm{p}$ region (Figure 2d) showed spin-orbit doublet peaks at 1044.49 and $1021.41 \mathrm{eV}$ corresponding to $\mathrm{Zn} 2 \mathrm{p}_{1 / 2}$ and $2 \mathrm{p}_{3 / 2}$, respectively. The morphology of the COF-TPP-CB[6] was investigated using TEM and SEM which showed a porous structure (Figures 3a,b and S16). The average particle size of the sample was estimated by TEM to be around $40-50 \mathrm{~nm}$. The SEM/ EDX elemental mapping for the distribution of $\mathrm{C}, \mathrm{N}, \mathrm{O}$, and $\mathrm{Zn}$ in the COF-TPP-CB[6] along with the corresponding EDX spectrum and atomic percentage of elements are shown in Figures $2 c$ and S17, respectively. Powder XRD pattern of COF-TPP-CB[6] was recorded (Figure S18a) and showed a crystalline structure with well-defined diffraction peaks at $2 \theta=$ $8.2^{\circ}, 18.1^{\circ}, 22.1^{\circ}$, and 28.3. The comparison of XRD spectra of COF-TPP-CB [6] and its monomers, TPP-Zn- $4 \mathrm{~N}_{3}$ and perpropargyloxy-CB[6], was also provided in Figure $\mathrm{S} 18 \mathrm{~b}$.

The textural properties of the COF-TPP-CB[6] were studied using nitrogen physisorption at $-196{ }^{\circ} \mathrm{C}$, and the results were illustrated in Figures S19-S21. The nitrogen physisorption isotherms (Figure S19) exhibited a Type III isotherm according to the IUPAC classification. The specific surface area and total specific pore volume of the sample calculated with the Brunauer-Emmett-Teller (BET) and Barrett-Joyner-Halenda $(\mathrm{BJH})$ models were found to be $33.17 \mathrm{~m}^{2} \mathrm{~g}^{-1}$ and $0.34 \mathrm{~cm}^{3} \mathrm{~g}^{-1}$, respectively. Pore radius and pore width were measured as 11.74 and $2.41 \mathrm{~nm}$, respectively. The BJH pore size distribution curve (Figure S21) confirms the presence of the mesoporosity in the range of $2-50 \mathrm{~nm}$. It was also revealed that the COF-TPP-CB $[6]$ is composed of agglomerated slit-like particles. Thermal stability of the developed COF-TPP-CB[6] was investigated with TGA analysis in the range of 25 to $900{ }^{\circ} \mathrm{C}$ with a rate of $10{ }^{\circ} \mathrm{C}$ $\mathrm{min}^{-1}$ under nitrogen atmosphere (Figure S22). The TGA curve exhibited four types of decomposition. The first decomposition (20\%) below $200{ }^{\circ} \mathrm{C}$ is due to the loss of hydroxyl groups and adsorbed water molecules, the second decomposition $(10 \%)$ around $210{ }^{\circ} \mathrm{C}$ is probably due to the loss of free azide groups from the compound, the third one (a)

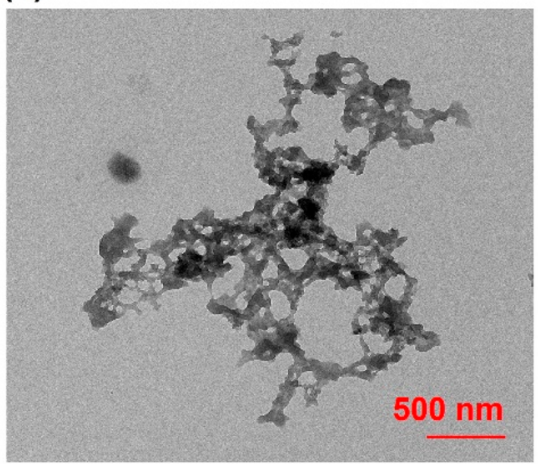

(b)

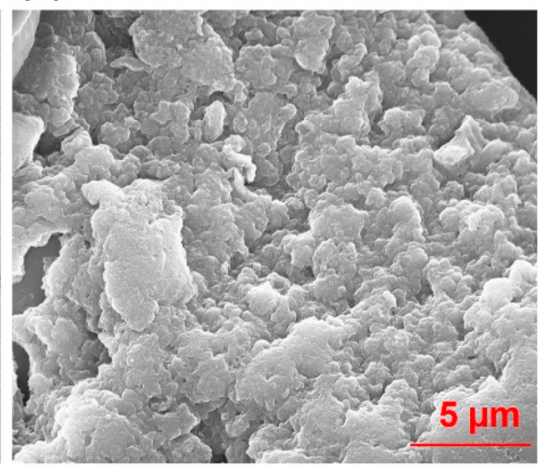

(c)

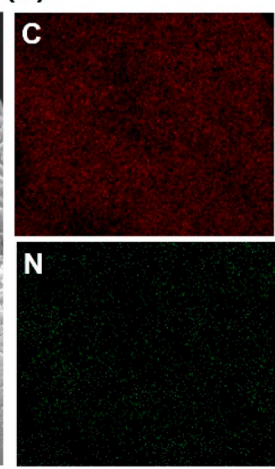

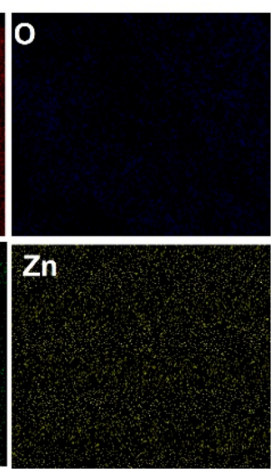

Figure 3. (a) TEM image, (b) SEM image, and (c) the corresponding EDX elemental mapping images of COF-TPP-CB[6]. 
(10\%) at $403{ }^{\circ} \mathrm{C}$ arises from the loss of benzene rings attached to the core, and from $550{ }^{\circ} \mathrm{C}$, the sample itself started to gradually decompose.

3.2. Evaluation of the Electrocatalytic HER Activity of COF-TPP-CB[6]. Once we authenticated the structure of the developed COF-TPP-CB[6] by detailed characterization, we next carried out electrochemical studies to evaluate its catalytic performance to produce hydrogen from water splitting. Herein, the main features of our designed assembly include: electrochemically active porphyrin cores as building units with rich multielectron redox chemistry, multifunctionalities such as triazole units, and carbonyl groups at the CBs portals that may coordinate with the metal cocatalyst $(\mathrm{Ni})$ for efficient energy transfer, providing chemical stability to the assembly. Electrochemical studies were begun with COF-TPP-CB $[6]$ containing $\mathrm{TiO}_{2}$. The ink was prepared by the grinding of COF-TPPCB [6] with $\mathrm{TiO}_{2}$ (ratio 1:2) and then mixing of the nanocomposite with water, ethanol, and nafion without any sacrificial agent. The mixture was stirred overnight. A known volume of the prepared ink was then drop cast onto a clean fluorine-doped tin oxide (FTO) glass $\left(2 \times 1 \mathrm{~cm}^{2}\right)$ covering an $1 \times 1 \mathrm{~cm}^{2}$ area. The ink was simply dried at room temperature to get a thin COF-TPP-CB[6]-TiO 2 film over FTO. A detailed procedure of ink preparation was described in the SI.

The electrocatalytic HER performance of the COF-TPP$\mathrm{CB}[6]-\mathrm{TiO}_{2}$ nanocomposite was first examined in three different electrolytes, namely, acidic $\left(0.25 \mathrm{M} \mathrm{H}_{2} \mathrm{SO}_{4}\right)$, neutral (0.1 M PBS), and basic $(0.1 \mathrm{M} \mathrm{KOH})$ by performing linear sweep voltammetry (LSV) measurement with a scan rate of 10 $\mathrm{mV} \mathrm{s}^{-1}$ under the Ar-saturated conditions. Representative LSV curves of geometric current density $\left(\mathrm{mA} \mathrm{cm}{ }^{-2}\right)$ vs applied potential were presented in Figure $4 \mathrm{a}$. All the measured potentials are referred to a reversible hydrogen electrode (RHE) based on the Nernst equation. As shown in Figure 4a, COF-COF-TPP-CB $[6]-\mathrm{TiO}_{2}$ catalyst exhibited a very low cathodic current density with the most negative onset potential (at which the reduction is started) of $-700 \mathrm{mV}$ in neutral
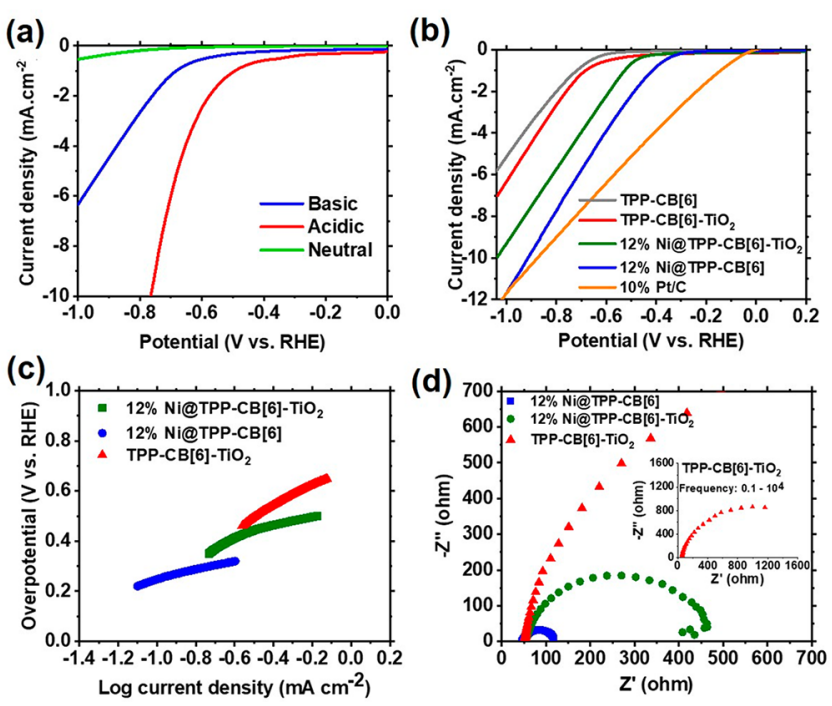

Figure 4. (a) LSV Polarization curves of COF-TPP-CB[6]-TiO catalyst at $10 \mathrm{mV} \mathrm{s}^{-1}$ in various electrolyte media, (b) LSV polarization curves obtained at $10 \mathrm{mV} \mathrm{s}^{-1}$ in $0.1 \mathrm{M} \mathrm{KOH}$, (c) corresponding Tafel plots in the linear region, and (d) Nyquist plots measured at $-0.4 \mathrm{~V}$ vs RHE for COF-TPP-CB[6]-TiO $2,12 \% \mathrm{Ni} @$ COF-TPP-CB $[6]-\mathrm{TiO}_{2}$, and 12\%Ni@COF-TPP-CB[6] catalysts. medium. Although the COF-TPP-CB $[6]-\mathrm{TiO}_{2}$ catalyst exhibited a less negative onset potential of $-360 \mathrm{mV}$ with high cathodic current density in acidic electrolyte, it was degraded and peeled off during the first run of LSV measurement. Meanwhile, the nanocomposite exhibited moderate HER performance (onset potential $-500 \mathrm{mV}$ ), however high stability in the basic medium as it survived repeated cycles of measurements. Thus $0.1 \mathrm{M} \mathrm{KOH}$ electrolyte was chosen as the optimal condition for further experiments. Aiming to improve the HER electrocatalytic performance of the COF-TPP-CB $[6]-\mathrm{TiO}_{2}$ catalyst in alkaline medium, nickel $(\mathrm{Ni})$ was introduced as a cocatalyst by grinding the nanocomposite with a known amount of nickel acetate salt to obtain $12 \% \mathrm{Ni}$ loading. Enormous efforts are being devoted for the development of noble-metal-free electrocatalysts. Therein, electrocatalysts derived from earth-abundant transition metals such as $\mathrm{Ni}, \mathrm{Co}$, and $\mathrm{Fe}$ have been investigated as promising and cost-effective alternatives in both acidic and alkaline electrolytes. ${ }^{46}$ The special $3 \mathrm{~d}$ electronic distribution of $\mathrm{Ni}$ has given rise to considerable application of Ni-based catalysts toward hydrogen production in the alkaline medium. ${ }^{47}$ Moreover, Direct use of nickel acetate powder with the catalyst provides a straightforward and cost-effective method to boost the electrocatalytic activity. Meanwhile, we also prepared 12\%Ni@COF-TPP-CB[6] catalyst to study the $\mathrm{Ni}$ effect in the absence $\mathrm{TiO}_{2}$. The polarization curves of the samples were exhibited in Figure $4 \mathrm{~b}$. Insertion of $\mathrm{Ni}$ into the nanocomposite had significant impact on the activity of COFTPP-CB $[6]-\mathrm{TiO}_{2}$ by shifting the onset potential from -500 $\mathrm{mV}$ to more positive value of $-300 \mathrm{mV}$ as well as increasing the cathodic current density. Most remarkably, it was observed that the metalated catalyst without $\mathrm{TiO}_{2}$ showed the best HER performance with the lowest onset potential of $-250 \mathrm{mV}$ as well as the turn over frequency (TOF) value of $0.101 \mathrm{~s}^{-1}$. The electrocatalytic activity of the catalysts increased in the order of COF-TPP-CB $[6]<$ COF-TPP-CB $[6]-\mathrm{TiO}_{2}<12 \% \mathrm{Ni@COF-}$ TPP-CB $[6] \mathrm{TiO}_{2}<12 \% \mathrm{Ni} @$ COF-TPP-CB $[6]$.

In order to acquire more details on the electrocatalytic kinetics of the studied catalysts, Tafel plots were derived from the linear regions of the LSV curves by plotting overpotential against log current density ${ }^{48}$ (Figure $4 \mathrm{c}$ ). A Tafel slope is employed to evaluate the kinetics of the system. A lower Tafel slop signifies the faster electrode kinetics. COF-TPP-CB[6]$\mathrm{TiO}_{2}$ had the highest Tafel slope of $379 \mathrm{mV} \mathrm{dec}^{-1}$, a value

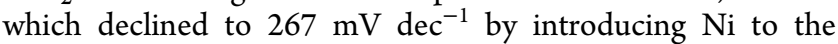
nanocomposite. The lowest Tafel slope was achieved by a $\mathbf{1 2 \%}$ Ni@COF-TPP-CB[6] catalyst without $\mathrm{TiO}_{2}\left(195 \mathrm{mV} \mathrm{dec}^{-1}\right)$, suggesting the fastest kinetics among the other samples, and it is comparable with other examples of porphyrin-based and nonprecious metal electrocatalysts reported in the literature. $^{5,41,49}$ Exchange current density (ECD, $\left.i_{0}\right)$ as another important kinetics parameter from the Tafel plot is proportional to the rate of an electrochemical reaction. The higher the ECD, the faster electrochemical reaction. 12\%Ni@COF-TPPCB[6] exhibited higher ECD of $0.362 \mathrm{~mA} \mathrm{~cm}^{-2}$ compared to 12\%Ni@COF-TPP-CB[6]-TiO $2\left(0.272 \mathrm{~mA} \mathrm{~cm}^{-2}\right)$ and faster electrochemical reaction as well. The obtained electrochemical parameters for the studied samples were given in Table S1. Electrochemical calculations were fully described in the SI.

The electrochemical impedance spectroscopy (EIS) was applied to study the interfacial charge transfer resistance of samples. The experiments were conducted at $-0.4 \mathrm{~V}$ vs $\mathrm{RHE}$ in $0.1 \mathrm{M} \mathrm{KOH}$ for frequency range of $0.1 \mathrm{~Hz}$ to $10 \mathrm{kHz}$. 
Nyquist plots for the samples were presented in Figure 4d. According to these plots, samples only exhibited the semicircle behavior in the high frequency region. Warburg impedance was not observed in the low frequency region, implying that rapid electron transfer in the electrolyte resulted in kinetically controlled electrochemical reaction on the electrode surface. COF-TPP-CB $[6]-\mathrm{TiO}_{2}$ possessed the largest semicircle radius which can be defined as the highest amount of charge transfer resistance $\left(R_{\mathrm{ct}}\right.$ of $\left.1727.00 \Omega\right)$. Introducing $\mathrm{Ni}$ in the composite decreased $R_{\mathrm{ct}}$ hugely, resulting in fast electron transfer at the interface. Therein, 12\%Ni@COF-TPP-CB[6] in the absence of $\mathrm{TiO}_{2}$ showed the lowest $R_{\mathrm{ct}}$ of $68.60 \Omega$, which entails that charge carriers would confront smaller charge transfer resistance at the electrode-electrolyte interface. The conjugated $\pi$ electronic structure of the framework can contribute to this high charge transfer capacity. ${ }^{43}$ The obtained resistance values for the samples were given in Table S2.

We also measured the double layer capacitance $\left(C_{\mathrm{dl}}\right)$ of $\mathbf{1 2 \%}$ $\mathrm{Ni@COF-TPP-CB}[6]$ compared to 12\%Ni@COF-TPP$\mathrm{CB}[6]-\mathrm{TiO}_{2}$ by performing a series of cyclic voltammetry (CV) measurements in nonfaradaic region of 0 to $0.1 \mathrm{~V}$ vs $\mathrm{Ag} /$ $\mathrm{AgCl}$ at different scan rates (Figure S23a-d, see SI for more experimental details). The results showed that 12\%Ni@COFTPP-CB[6] exhibited a larger $C_{\mathrm{dl}}$ value of $45.11 \mu \mathrm{F} \mathrm{cm}$ compared to $12 \% \mathrm{Ni@COF-TPP-CB}[6]-\mathrm{TiO}_{2} \quad(30.27 \mu \mathrm{F}$ $\mathrm{cm}^{-2}$ ), indicating a higher available electrochemical active surface area (ECSA) which may be responsible for the better electrocatalytic activity of this sample.

Overall, the higher HER performance of 12\%Ni@COFTPP-CB $[6]$ catalyst compared to COF-TPP-CB $[6]-\mathrm{TiO}_{2}$ and $12 \% \mathrm{Ni} @$ COF-TPP-CB $[6]-\mathrm{TiO}_{2}$ can be attributed to the free carbonyl groups of the $\mathrm{CB}[6]$ of the framework in the absence of $\mathrm{TiO}_{2}$ that coordinate with water molecules and facilitate the HER reaction. Effect of $\mathrm{Ni}$ amount on the HER performance of the Ni@COF-TPP-CB[6] catalyst was further studied by preparing four inks with different $\mathrm{Ni}$ loadings in the range from $6 \%$ to $47 \%$. The LSV measurements were conducted under the same experimental conditions, and the obtained curves were shown in Figure 5a in comparison with bare FTO. The results indicated that increasing the $\mathrm{Ni}$ content from $6 \%$ to $12 \%$ enhanced the HER performance of the electrocatalyst. However, a further increase in the $\mathrm{Ni}$ content diminished the electrocatalytic activity where 47\%Ni@COF-TPP-CB[6] showed the highest onset potential $(-400 \mathrm{mV})$ and the lowest cathodic current density among the samples. This can be attributed to the fact that extra $\mathrm{Ni}$ in the catalyst may cause saturation of the active site density. Herein, 12\% Ni@COFTPP-CB [6] as the optimum sample exhibited improved HER ability with lowest onset potential of $-250 \mathrm{mV}$ and required the lowest overpotential $(\eta)$ of -0.416 and $-0.914 \mathrm{~V}$ to reach the current density of 1.0 and $10 \mathrm{~mA} \mathrm{~cm}{ }^{-2}$, respectively, among the other aforementioned systems. The obtained results are comparable with the porphyrin-based catalysts reported in the literature such as ERGO@CoTMPyP possessing $\eta @ 1 \mathrm{~mA}$ $\mathrm{cm}^{-2}$ of $-0.474 \mathrm{~V}$ in the alkaline media. ${ }^{50}$ The Tafel plots of Ni@TPP-CB[6] samples and corresponding electrochemical parameters as well as TOF values for all Ni@TPP-CB[6] systems were presented in Figure S24 and Table S1, respectively.

EIS measurement was also performed for comparing the charge transfer resistance of Ni@TPP-CB [6] systems containing various amounts of $\mathrm{Ni}$. According to the Nyquist plots shown in Figure $5 b$, these samples only exhibited the
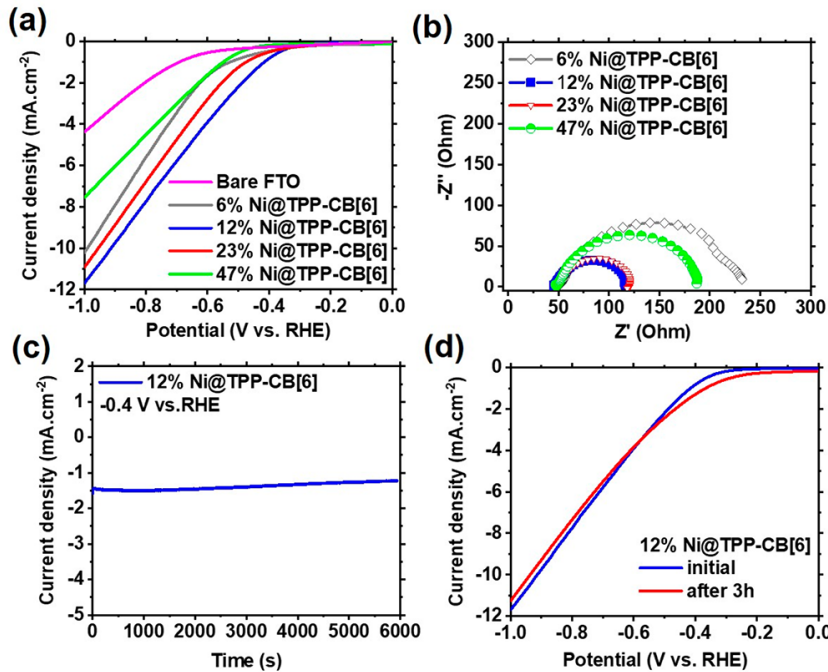

(d)

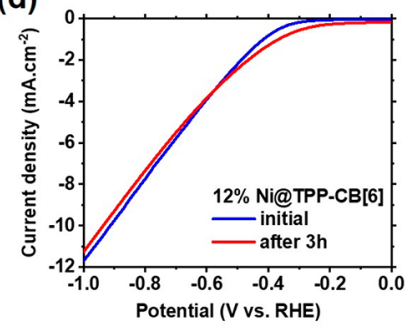

Figure 5. (a) LSV polarization curves for Ni@COF-TPP-CB[6] with different $\mathrm{Ni}$ content obtained at $10 \mathrm{mV} \mathrm{s}^{-1}$ in $0.1 \mathrm{M} \mathrm{KOH}$, and (b) the corresponding Nyquist plots recorded at $-0.4 \mathrm{~V}$ vs RHE in $0.1 \mathrm{M}$ $\mathrm{KOH},(\mathrm{c})$ chronoamperometry experiments of 12\%Ni@COF-TPPCB[6] under constant potential of $-0.4 \mathrm{~V}$ vs RHE in $0.1 \mathrm{M} \mathrm{KOH}$, and (d) the corresponding polarization curves of 12\%Ni@COF-TPP$\mathbf{C B}[6]$ before and after $3 \mathrm{~h}$ durability experiment obtained at $10 \mathrm{mV}$ $\mathrm{s}^{-1}$ in $0.1 \mathrm{M} \mathrm{KOH}$.

semicircle behavior in the high frequency region. It was found that the $R_{\mathrm{ct}}$ value of all systems decreased in the order of $6 \%$ Ni@COF-TPP-CB $[6]>47 \% N i @ C O F-T P P-C B[6]>23 \%$ $\mathrm{Ni@COF-TPP-CB}[6]>12 \% \mathrm{Ni@COF-TPP-CB}[6]$, which is in consistent with the results obtained from LSV studies. The resistance values obtained for these samples were given in Table S2. Overall, 12\%Ni@COF-TPP-CB[6] showed the lowest $R_{\mathrm{ct}}$ and best electrocatalytic HER performance among the other systems. The electrochemical behavior of $12 \% \mathrm{Ni}$ COF-TPP-CB [6] can be modeled by a simple Rendles equivalent circuit as shown in Figure S25b. The resistance due to uncompensated electrolyte solution is presented by $R_{\mathrm{s}}$ which is about $46.66 \Omega$. The diameter of the semicircle arc, $R_{c t}$ value, was calculated to be about $68.60 \Omega$ and this value is quite comparable with those obtained from other reported HER electrocatalysts in the literature. ${ }^{43,51}$ Polarization curve of the 12\%Ni@COF-TPP-CB[6] was manually corrected for $i R$ drop using the $R_{\mathrm{s}}$ from the EIS measurement. As depicted in Figure S25c, the potential window shortened significantly and the current density of $10 \mathrm{~mA} \mathrm{~cm}{ }^{-2}$ could be obtained at a less negative $\eta$ of $-0.513 \mathrm{~V}$ vs $\mathrm{RHE}$ compared to the uncompensated value of $-0.914 \mathrm{~V}$ vs RHE.

Durability of electrode is a crucial factor in functionality of HER electrocatalysts. Durability of the 12\%Ni@COF-TPPCB [6] catalyst was examined using the chronoamperometry (CA) method conducted under constant potential of $-0.4 \mathrm{~V}$ vs RHE in $0.1 \mathrm{M} \mathrm{KOH}$. The current-time plot in Figure 5c revealed that the current response of the electrocatalyst was almost stable over $6000 \mathrm{~s}$ experiment, indicating that the hydrogen production capability of the electrode remained unchanged. Moreover, the LSV polarization curve of the catalyst after $3 \mathrm{~h}$ durability experiment was recorded and showed that there was no significant change in the HER performance of the catalyst (Figure $5 \mathrm{~d}$ ).

The morphology and particle size of 12\% Ni@COF-TPPCB $[6]$ were characterized by TEM (Figure 6). The TEM 


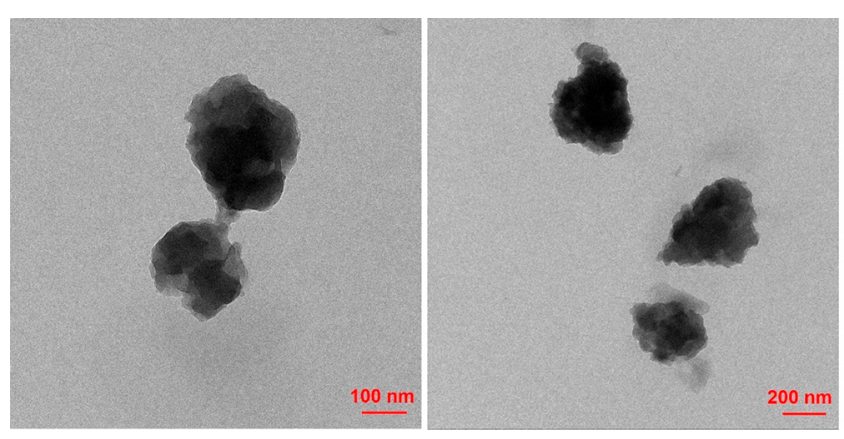

Figure 6. TEM images of 12\% Ni@COF-TPP-CB[6].

images illustrate irregular particles with an average length and width around 350 and $250 \mathrm{~nm}$, respectively. 12\% Ni@COFTPP-CB[6]-FTO electrode was characterized SEM, XPS, and XRD techniques before and after $3 \mathrm{~h}$ durability experiment (Figure S26-S28). The SEM images showed that the morphology of the sample did not collapse after CA experiments (Figure S26a,c). SEM/EDX elemental mapping results were also indicated similar morphology before and after catalysis (Figure S26b,d). By comparing the high resolution XPS spectra of 12\% Ni@COF-TPP-CB[6] before and after 3 h CA experiment given in Figure S27a,b, it can be noticed that the electrocatalyst did not undergo any significant change and retained its chemical composition. The Ni $2 p$ XPS spectrum of 12\% Ni@COF-TPP-CB $[6]$ deconvoluted into eight peaks, which were assigned to the $\mathrm{Ni}^{2+} 2 \mathrm{p}_{3 / 2}, \mathrm{Ni}^{2+} 2 \mathrm{p}_{1 / 2}$, and satellite peaks. The Ni $2 p_{3 / 2}$ XPS spectrum presented an asymmetric doublet peak, with the main peak located at $856.3 \mathrm{eV}$ and a minor peak at $853.3 \mathrm{eV}$, which can be assigned to $\mathrm{Ni}(\mathrm{OH})_{2}$ and $\mathrm{NiO}$, respectively, and satellite peaks at 861 and 864 $\mathrm{eV}{ }^{52,53}$ For the Ni $2 \mathrm{p}_{1 / 2}$ XPS spectrum, the main peak located at $874 \mathrm{eV}$, the minor peak at $870.4 \mathrm{eV}$, and the satellite peaks at 879 and $882.4 \mathrm{eV}$, respectively. The $\mathrm{Zn} 2 \mathrm{p}$ XPS spectrum showed the same peaks as before the CA experiment and the $\mathrm{Zn}-\mathrm{N}$ binding (at $397.6 \mathrm{eV}$ ) in $\mathrm{N}$ 1s spectrum confirmed the presence of $\mathrm{Zn}$ in the core of porphyrin rings even after $\mathrm{CA}$ experiment.

The amount of $\mathrm{H}_{2}$ produced can be estimated using the Faraday law (see electrochemical calculations in the SI). Accordingly, 12\%Ni@TPP-CB[6] as the optimum catalyst was able to evolve $18.7 \mathrm{mmol} \mathrm{h}^{-1} \mathrm{~g}^{1}$ hydrogen, contributing to a faradaic efficiency of $85 \%$. In comparison the amounts of produced hydrogen for TPP-CB[6]- $\mathrm{TiO}_{2}$ and $12 \% \mathrm{Ni} @ \mathrm{TPP}-$ $\mathrm{CB}[6]-\mathrm{TiO}_{2}$ were calculated as $7.9 \mathrm{mmol} \mathrm{h}^{-1} \mathrm{~g}^{-1}$ and 11.9 mmol $\mathrm{h}^{-1} \mathrm{~g}^{-1}$, respectively. The amounts of hydrogen produced by all the catalysts studied in this work were plotted in Figure S28.

\section{CONCLUSIONS}

A new covalent organic framework based on the TPP-Zn- $4 \mathbf{N}_{3}$ and covalently attached $\mathbf{C B} 6(\mathbf{O}-\mathbf{P})_{n}$ was successfully synthesized through $\mathrm{Cu}-\mathrm{AAC}$ reaction and then fully characterized. $\mathrm{CB6}(\mathrm{O}-\mathrm{P})_{n}$ was synthesized by O-propargylation of the assynthesized $\mathbf{C B 6}(\mathrm{OH})_{n}$. The presence of $\mathbf{C B}[6]$ and electroactive porphyrin cores along with multifunctionalities made the developed COF-TPP-CB[6] a good candidate for electrocatalytic hydrogen evolution from water splitting. The effect of $\mathrm{TiO}_{2}$ and various loadings of $\mathrm{Ni}$ on the electrocatalytic HER performance of COF-TPP-CB[6] in alkaline medium was investigated and it was found that its electrocatalytic activity showed significant improvement upon introducing only $12 \%$ $\mathrm{Ni}$ without any $\mathrm{TiO}_{2}$. Under optimal conditions, 12\%Ni@ COF-TPP-CB[6] catalyst exhibited high performance and good durability for HER and produced $18.7 \mathrm{mmol} \mathrm{g}^{-1} \mathrm{~h}^{-1}$ of hydrogen (Faradaic efficiency of $85 \%$ ), which is comparable and even better than other porphyrin-based HER electrocatalysts reported in the literature (Table S3). 5,9,36,42,54-60

\section{ASSOCIATED CONTENT}

\section{Supporting Information}

The Supporting Information is available free of charge at https://pubs.acs.org/doi/10.1021/acsaem.0c03265.

Figures S1-S29, ${ }^{1} \mathrm{H}$ NMR, ESI-MS, and FT-IR spectra of $\mathrm{CB} 6(\mathrm{OH})_{n} ;{ }^{1} \mathrm{H}$ NMR, ESI-MS, and FTIR spectra of $\mathbf{C B 6}(\mathrm{O}-\mathrm{P})_{n}$; ${ }^{1} \mathrm{H}$ NMR, ESI-MS, FT-IR, and UV-vis absorbance of TPP-4N ${ }_{3} ;{ }^{1} \mathrm{H}$ NMR, ESIMS, FT-IR, and UV-vis absorbance of TPP-Zn- $\mathbf{4 N} \mathbf{N}_{3}$; ${ }^{1} \mathrm{H}$ NMR spectrum of TPP-CB[6]; TEM image and SEM/EDX spectrum of COF-TPP-CB[6] and the corresponding atomic percentage of elements; XRD spectrum of COF-TPP-CB [6] and the comparison with its monomers; $\mathrm{N}_{2}$ physisorption isotherm of COF-TPP$\mathrm{CB}[6]$; multipoint $\mathrm{BET}, \mathrm{BJH}$ pore size distribution of COF-TPP-CB[6]; TGA graph of COF-TPP-CB[6]; curves related to the determination of the double layer capacitance of $12 \% \mathrm{Ni@} \mathrm{COF-TPP-CB}[6]-\mathrm{TiO}_{2}$ and 12\% Ni@COF-TPP-CB[6] catalysts; Tafel plots of Ni@COF-TPP-CB $[6]$ catalysts; polarization curve with and without $i R$ correction for 12\% Ni@COF-TPPCB $[6]$ and 10\%Pt/C; SEM images of 12\% Ni@COFTPP-CB [6] before and after CA; XPS data of 12\% Ni@ TPP-CB $[6]$ before and after CA; XRD spectra of $12 \%$ Ni@COF-TPP-CB $[6]$ before and after CA; comparison of the hydrogen produced by studied electrocatalyst in $0.1 \mathrm{M} \mathrm{KOH}$; Tables $\mathrm{S} 1-\mathrm{S} 3$, electrochemical parameters of different studied electrocatalysts toward HER in 0.1 $\mathrm{M} \mathrm{KOH}$; resistance values obtained from Nyquist plots for samples with various Ni loading; and a comparison of produced hydrogen and experimental conditions of different porphyrin-based catalysts (PDF)

\section{AUTHOR INFORMATION}

\section{Corresponding Author}

Dönüs Tuncel - Institute of Materials Science and Nanotechnology, National Nanotechnology Research Center (UNAM) and Department of Chemistry, Bilkent University, 06800 Ankara, Turkey; $\odot$ orcid.org/0000-0001-7762-

9200; Email: dtuncel@fen.bilkent.edu.tr

\section{Authors}

Aisan Khaligh - Institute of Materials Science and Nanotechnology, National Nanotechnology Research Center (UNAM) and Department of Chemistry, Bilkent University, 06800 Ankara, Turkey; (1) orcid.org/0000-0002-5419-1020

Yasaman Sheidaei - Institute of Materials Science and Nanotechnology, National Nanotechnology Research Center (UNAM), Bilkent University, 06800 Ankara, Turkey

Complete contact information is available at:

https://pubs.acs.org/10.1021/acsaem.0c03265

\section{Notes}

The authors declare no competing financial interest. 


\section{ACKNOWLEDGMENTS}

We thank Mr. S. E. Hadi for his assistance in the TGA.

\section{ABBREVIATIONS USED}

NMR, nuclear magnetic resonance

FT-IR, Fourier-transform infrared spectroscopy

TGA, thermogravimetric analysis

SEM, scanning electron microscopy

TEM, transmission electron microscopy

EDX, energy dispersive X-ray

$\mathrm{XRD}, \mathrm{X}$-ray diffractometer

XPS, X-ray photoelectron spectroscopy

UV-vis, ultraviolet-visible

ESI-MS, electrospray ionization mass spectrometry

BET, Brunauer-Emmett-Teller

$\mathrm{Cu}$-AAC, copper-catalyzed azide-alkyne cycloaddition reaction

$\mathrm{CB}[6]$, cucurbit $[6]$ uril

$\mathrm{CB} 6(\mathrm{OH})_{n}$, perhydroxy-CB $[6]$

$\mathrm{CB} 6(\mathrm{O}-\mathrm{P})_{n}$, perpropargyloxy- $\mathrm{CB}[6]$

TPP-4Br, 5,10,15,20-tetrakis $(\alpha$-bromo-p-tolyl)porphyrin

TPP-4N $3,5,10,15,20$-tetrakis $(\alpha$-azido- $p$-tolyl) porphyrin

TPP-Zn- $4 N_{3}, T P P-4 N_{3}$ with $\mathrm{Zn}(\mathrm{II})$ metalated porphyrin core

TPP-CB $[6]$, covalently conjugated TPP-Zn-4N 3 with $\mathrm{CB} 6(\mathrm{O}-\mathrm{P})_{n}$

$\mathrm{COF}$, covalent organic framework

$\mathrm{Ni}$, Nickel

$\mathrm{TiO}_{2}$, titanium dioxide

LSV, linear sweep voltammetry

CA, chronoamperometry

HER, hydrogen evolution reaction.

\section{REFERENCES}

(1) Kolesnichenko, I. V.; Anslyn, E. V. Practical Applications of Supramolecular Chemistry. Chem. Soc. Rev. 2017, 46, 2385-2390.

(2) Koc, A.; Tuncel, D. Supramolecular Assemblies of Cucurbiturils with Photoactive, $\pi$-Conjugated Chromophores. Isr. J. Chem. 2018, $58,334-342$.

(3) Savyasachi, A. J.; Kotova, O.; Shanmugaraju, S.; Bradberry, S. J.; ÓMáille, G. M.; Gunnlaugsson, T. Supramolecular Chemistry: A Toolkit for Soft Functional Materials and Organic Particles. Chem. 2017, 3, 764-811.

(4) Beletskaya, I.; Tyurin, V. S.; Tsivadze, A. Y.; Guilard, R.; Stern, C. Supramolecular Chemistry of Metalloporphyrins. Chem. Rev. 2009, 109, 1659-1713.

(5) Canales, C.; Varas-Concha, F.; Mallouk, T. E.; Ramírez, G. Enhanced Electrocatalytic Hydrogen Evolution Reaction: Supramolecular Assemblies of Metalloporphyrins on Glassy Carbon Electrodes. Appl. Catal., B 2016, 188, 169-176.

(6) Lee, H.; Hong, K.-I.; Jang, W.-D. Design and Applications of Molecular Probes Containing Porphyrin Derivatives. Coord. Chem. Rev. 2018, 354, 46-73.

(7) Yang, J.; Yoon, M.-C.; Yoo, H.; Kim, P.; Kim, D. Excitation Energy Transfer in Multiporphyrin Arrays with Cyclic Architectures: Towards Artificial Light-Harvesting Antenna Complexes. Chem. Soc. Rev. 2012, 41, 4808-4826.

(8) Rajora, M.; Lou, J.; Zheng, G. Advancing Porphyrin's Biomedical Utility via Supramolecular Chemistry. Chem. Soc. Rev. 2017, 46, 6433-6469.

(9) Beyene, B. B.; Mane, S. B.; Hung, C.-H. Highly Efficient Electrocatalytic Hydrogen Evolution from Neutral Aqueous Solution by a Water-Soluble Anionic Cobalt(II) Porphyrin. Chem. Commun. 2015, 51, 15067-15070.
(10) Lu, G.; Zhu, Y.; Xu, K.; Jin, Y.; Ren, Z. J.; Liu, Z.; Zhang, W. Metallated Porphyrin Based Porous Organic Polymers as Efficient Electrocatalysts. Nanoscale 2015, 7, 18271-18277.

(11) Vinodh, M.; Alipour, F. H.; Mohamod, A. A.; Al-Azemi, T. F. Molecular Assemblies of Porphyrins and Macrocyclic Receptors: Recent Developments in Their Synthesis and Applications. Molecules 2012, 17, 11763-11799.

(12) Zhang, Z.; Kim, D. S.; Lin, C.-Y.; Zhang, H.; Lammer, A. D.; Lynch, V. M.; Popov, I.; Miljanić, O. S.; Anslyn, E. V.; Sessler, J. L. Expanded Porphyrin-Anion Supramolecular Assemblies: Environmentally Responsive Sensors for Organic Solvents and Anions. J. Am. Chem. Soc. 2015, 137, 7769-7774.

(13) Drain, C. M.; Varotto, A.; Radivojevic, I. Self-Organized Porphyrinic Materials. Chem. Rev. 2009, 109, 1630-1658.

(14) Gust, D.; Moore, T. A.; Moore, A. L. Solar Fuels via Artificial Photosynthesis. Acc. Chem. Res. 2009, 42, 1890.

(15) Urbani, M.; Grätzel, M.; Nazeeruddin, M. K.; Torres, T. MesoSubstituted Porphyrins for Dye-Sensitized Solar Cells. Chem. Rev. 2014, 114, 12330.

(16) Longevial, J. F.; Clément, S.; Wytko, J. A.; Ruppert, R.; Weiss, J.; Richeter, S. Peripherally Metalated Porphyrins with Applications in Catalysis, Molecular Electronics and Biomedicine. Chem. - Eur. J. 2018, 24, 15442-15460.

(17) Girek, B.; Sliwa, W. Noncovalent Assemblies of Cationic Porphyrins with Cage Macrocycles. J. Inclusion Phenom. Macrocyclic Chem. 2015, 81, 35-48.

(18) Tuncel, D.; Cindir, N.; Koldemir, Ü. [5]Rotaxane and [5]Pseudorotaxane Based on Cucurbit[6]uril and Anchored to a Meso-Tetraphenyl Porphyrin. J. Inclusion Phenom. Mol. Recognit. Chem. 2006, 55, 373-380.

(19) Liu, S.; Shukla, A. D.; Gadde, S.; Wagner, B. D.; Kaifer, A. E.; Isaacs, L. Ternary Complexes Comprising Cucurbit[10]uril, Porphyrins, and Guests. Angew. Chem. 2008, 120, 2697-2700.

(20) Mohanty, J.; Bhasikuttan, A. C.; Choudhury, S. D.; Pal, H. Noncovalent Interaction of 5, 10, 15, 20-tetrakis(4-N-methylpyridyl) Porphyrin with Cucurbit[7]uril: A Supramolecular Architecture. $J$. Phys. Chem. B 2008, 112, 10782-10785.

(21) Barooah, N.; Bhasikuttan, A. C.; Sudarsan, V.; Choudhury, S. D.; Pal, H.; Mohanty, J. Surface Functionalized Silver Nanoparticle Conjugates: Demonstration of Uptake and Release of a Phototherapeutic Porphyrin Dye. Chem. Commun. 2011, 47, 9182-9184.

(22) Lei, W.; Jiang, G.; Zhou, Q.; Hou, Y.; Zhang, B.; Cheng, X.; Wang, X. Self-Assembly of Anionic Porphyrins and Alkaline or Alkaline Earth Metal Ions Mediated by Cucurbit [7, 8] uril. ChemPhysChem 2013, 14, 1003-1008.

(23) Liu, K.; Liu, Y.; Yao, Y.; Yuan, H.; Wang, S.; Wang, Z.; Zhang, $\mathrm{X}$. Supramolecular Photosensitizers with Enhanced Antibacterial Efficiency. Angew. Chem., Int. Ed. 2013, 52, 8285-8289.

(24) Chen, L.; Bai, H.; Xu, J.-F.; Wang, S.; Zhang, X. Supramolecular Porphyrin Photosensitizers: Controllable Disguise and Photoinduced Activation of Antibacterial Behavior. ACS Appl. Mater. Interfaces 2017, 9, 13950-13957.

(25) Cáceres, J.; Robinson-Duggon, J.; Tapia, A.; Paiva, C.; Gómez, M.; Bohne, C.; Fuentealba, D. Photochemical Behavior of Biosupramolecular Assemblies of Photosensitizers, Cucurbit[n]urils and Albumins. Phys. Chem. Chem. Phys. 2017, 19, 2574-2582.

(26) Chowdhury, S.; Nassar, Y.; Guy, L.; Frath, D.; Chevallier, F.; Dumont, E.; Ramos, A. P.; Demets, G. J.-F.; Bucher, C. Photo/RedoxResponsive 2D-Supramolecular Assembly Involving Cucurbit[8]uril and A Star-Shaped Porphyrin Tecton. Electrochim. Acta 2019, 316, 79-92.

(27) Lee, J. W.; Samal, S.; Selvapalam, N.; Kim, H.-J.; Kim, K. Cucurbituril homologues and Derivatives: New Opportunities in Supramolecular Chemistry. Acc. Chem. Res. 2003, 36, 621-630.

(28) Gürbüz, S.; Idris, M.; Tuncel, D. Cucurbituril-Based Supramolecular Engineered Nanostructured Materials. Org. Biomol. Chem. 2015, 13, 330-347. 
(29) Kim, K.; Selvapalam, N.; Ko, Y. H.; Park, K. M.; Kim, D.; Kim, J. Functionalized Cucurbiturils and Their Applications. Chem. Soc. Rev. 2007, 36, 267-279.

(30) Jon, S. Y.; Selvapalam, N.; Oh, D. H.; Kang, J.-K.; Kim, S.-Y.; Jeon, Y. J.; Lee, J. W.; Kim, K. Facile Synthesis of Cucurbit[n]uril Derivatives via Direct Functionalization: Expanding Utilization of Cucurbit[n]uril. J. Am. Chem. Soc. 2003, 125, 10186-10187.

(31) Dong, N.; He, J.; Li, T.; Peralta, A.; Avei, M. R.; Ma, M.; Kaifer, A. E. Synthesis and Binding Properties of Monohydroxycucurbit[7]uril: A Key Derivative for the Functionalization of Cucurbituril Hosts. J. Org. Chem. 2018, 83, 5467-5473.

(32) Shetty, D.; Khedkar, J. K.; Park, K. M.; Kim, K. Can We Beat the Biotin-Avidin Pair?: cucurbit[7]uril-Based Ultrahigh Affinity Host-Guest Complexes and Their Applications. Chem. Soc. Rev. 2015, 44, 8747-8761.

(33) Truxal, A. E.; Cao, L.; Isaacs, L.; Wemmer, D. E.; Pines, A. Directly Functionalized Cucurbit[7]uril as a Biosensor for the Selective Detection of Protein Interactions by ${ }^{129} \mathrm{Xe}$ hyperCEST NMR. Chem. - Eur. J. 2019, 25, 6108-6112.

(34) Koc, A.; Khan, R.; Tuncel, D. Clicked” Porphyrin-Cucurbituril Conjugate: A New Multifunctional Supramolecular Assembly Based on Triglycosylated Porphyrin and Monopropargyloxycucurbit [7] uril. Chem. - Eur. J. 2018, 24, 15550-15555.

(35) Özkan, M.; Keser, Y.; Koc, A.; Tuncel, D. Glycosylated Porphyrin-Cucurbituril Conjugate for Photodynamic Inactivation of Bacteria and Doxorubicin Carriage for Anticancer Drug Delivery. J. Porphyrins Phthalocyanines 2019, 23, 1406-1413.

(36) Kumar, Y.; Patil, B.; Khaligh, A.; Hadi, S. E.; Uyar, T.; Tuncel, D. Novel Supramolecular Photocatalyst Based on Conjugation of Cucurbit[7]uril to Non-Metallated Porphyrin for Electrophotocatalytic Hydrogen Generation from Water Splitting. ChemCatChem 2019, 11, 2994-2999.

(37) Özkan, M.; Kumar, Y.; Keser, Y.; Hadi, S. E.; Tuncel, D. n. s. Cucurbit[7]uril-Anchored Porphyrin-Based Multifunctional Molecular Platform for Photodynamic Antimicrobial and Cancer Therapy. ACS Appl. Bio Mater. 2019, 2, 4693-4697.

(38) Hu, Q.; Liu, X.; Zhu, B.; Fan, L.; Chai, X.; Zhang, Q.; Liu, J.; $\mathrm{He}, \mathrm{C}$; $\mathrm{Lin}, \mathrm{Z}$. Crafting $\mathrm{MoC}_{2}$-doped Bimetallic Alloy Nanoparticles Encapsulated within $\mathrm{N}$-doped Graphene as Roust Bifunctional Electrocatalysts for Overall Water Splitting. Nano Energy 2018, 50, 212-219.

(39) Liu, F. Q.; Liu, J. W.; Gao, Z.; Wang, L.; Fu, X.-Z.; Yang, L. X.; Tao, Y.; Yin, W. H.; Luo, F. Constructing Bimetal-Complex Based Hydrogen-Bonded Framework for Highly Efficient Electrocatalytic Water Splitting. Appl. Catal., B 2019, 258, 117973.

(40) Li, Y.; Sun, Y.; Qin, Y.; Zhang, W.; Wang, L.; Luo, M.; Yang, H.; Guo, S. Recent Advances on Water-Splitting Electrocatalysis Mediated by Noble-Metal-Based Nanostructured Materials. Adv. Energy Mater. 2020, 10, 1903120.

(41) Cui, S.; Qian, M.; Liu, X.; Sun, Z.; Du, P. A Copper PorphyrinBased Conjugated Mesoporous Polymer-Derived Bifunctional Electrocatalyst for Hydrogen and Oxygen Evolution. ChemSusChem 2016, 9, 2365-2373.

(42) Manton, J. C.; Hidalgo, D.; Frayne, L.; Brandon, M. P.; Vos, J. G.; Pryce, M. T. Electrocatalytic Hydrogen Evolution Using MetalFree Porphyrins. Int. J. Hydrogen Energy 2018, 43, 18843-18849.

(43) Patra, B. C.; Khilari, S.; Manna, R. N.; Mondal, S.; Pradhan, D.; Pradhan, A.; Bhaumik, A. A Metal-Free Covalent Organic Polymer for Electrocatalytic Hydrogen Evolution. ACS Catal. 2017, 7, 61206127.

(44) Tuncel, D.; Steinke, J. H. Catalytic Self-Threading: A New Route for the Synthesis of Polyrotaxanes. Macromolecules 2004, 37, 288-302.

(45) Tuncel, D.; Ünal, Ö.; Artar, M. Supramolecular Assemblies Constructed by Cucurbituril-Catalyzed Click Reaction. Isr. J. Chem. 2011, 51, 525-532.

(46) Mohammed-Ibrahim, J.; Sun, X. Recent Progress on Earth Abundant Electrocatalysts for Hydrogen Evolution Reaction (HER) in Alkaline Medium to Achieve Efficient Water Splitting-A Review. J. Energy Chem. 2019, 34, 111-160.

(47) Mahmood, N.; Yao, Y.; Zhang, J. W.; Pan, L.; Zhang, X.; Zou, J. J. Electrocatalysts for Hydrogen Evolution in Alkaline Electrolytes: Mechanisms, Challenges, and Prospective Solutions. Adv. Sci. 2018, 5, 1700464.

(48) Li, F.; Zhang, L.; Li, J.; Lin, X.; Li, X.; Fang, Y.; Huang, J.; Li, W.; Tian, M.; Jin, J.; Li, R. Synthesis of $\mathrm{Cu}-\mathrm{MoS}_{2} / \mathrm{rGO}$ Hybrid as non-Noble Metal Electrocatalysts for the Hydrogen Evolution Reaction. J. Power Sources 2015, 292, 15-22.

(49) Lačnjevac, U.; Jović, B.; Jović, V.; Krstajić, N. Determination of Kinetic Parameters for the Hydrogen Evolution Reaction on the Electrodeposited $\mathrm{Ni}-\mathrm{MoO}_{2}$ Composite Coating in Alkaline Solution. J. Electroanal. Chem. 2012, 677, 31-40.

(50) Huang, D.; Lu, J.; Li, S.; Luo, Y.; Zhao, C.; Hu, B.; Wang, M.; Shen, Y. Fabrication of Cobalt Porphyrin. Electrochemically Reduced Graphene Oxide Hybrid Films for Electrocatalytic Hydrogen Evolution in Aqueous Solution. Langmuir 2014, 30, 6990-6998.

(51) Guo, J.; Li, F.; Sun, Y.; Zhang, X.; Tang, L. OxygenIncorporated $\mathrm{MoS}_{2}$ Ultrathin Nanosheets Grown on Graphene for Efficient Electrochemical Hydrogen Evolution. J. Power Sources 2015 291, 195-200.

(52) El-Samanody, E.-S. A.; El-Sawaf, A. K.; Madkour, M. Synthesis, Crystal Structure, Spectral and Thermal Investigations of Morpholinyldithiocarbamate Complexes: A Novel Coordinated Precursors for Efficient Metal Oxide Nanophotocatalysts. Inorg. Chim. Acta 2019, 487, 307-315.

(53) Hao, J.; Wang, X.; Liu, F.; Han, S.; Lian, J.; Jiang, Q. Facile Synthesis $\mathrm{ZnS} / \mathrm{ZnO} / \mathrm{Ni}(\mathrm{OH})_{2}$ Composites Grown On Ni Foam: a Bifunctional Materials for Photocatalysts and Supercapacitors. Sci. Rep. 2017, 7 (1), 1-12.

(54) Yuan, Y.-J.; Tu, J.-R.; Ye, Z.-J.; Lu, H.-W.; Ji, Z.-G.; Hu, B.; Li, Y.-H.; Cao, D.-P.; Yu, Z.-T.; Zou, Z.-G. Visible-Light-Driven Hydrogen Production from Water in a Noble-Metal-Free System Catalyzed by Zinc Porphyrin Sensitized $\mathrm{MoS}_{2} / \mathrm{ZnO}$. Dyes Pigm. 2015, 123, 285-292.

(55) Bhunia, S.; Das, S. K.; Jana, R.; Peter, S. C.; Bhattacharya, S.; Addicoat, M.; Bhaumik, A.; Pradhan, A. Electrochemical StimuliDriven Facile Metal-Free Hydrogen Evolution from PyrenePorphyrin-Based Crystalline Covalent Organic Framework. ACS Appl. Mater. Interfaces 2017, 9, 23843-23851.

(56) Wang, J.; Zheng, Y.; Peng, T.; Zhang, J.; Li, R. Asymmetric Zinc Porphyrin Derivative-Sensitized Graphitic Carbon Nitride for Efficient Visible-Light-Driven $\mathrm{H}_{2}$ production. ACS Sustainable Chem. Eng. 2017, 5, 7549-7556.

(57) Gonuguntla, S.; Tiwari, A.; Madanaboina, S.; Lingamallu, G.; Pal, U. Revealing High Hydrogen Evolution Activity in Zinc Porphyrin Sensitized Hierarchical Porous $\mathrm{TiO}_{z}$ Photocatalysts. Int. J. Hydrogen Energy 2020, 45, 7508-7516.

(58) Li, H.; Jie, L.; Pan, J.; Kang, L.; Yao, J. Direct Photocatalytic Hydrogen Evolution from Water Splitting Using Nanostructures of Hydrate Organic Small Molecule as Photocatalysts. J. Mater. Chem. A 2016, 4, 6577-6584.

(59) Mukherjee, G.; Thote, J.; Aiyappa, H. B.; Kandambeth, S.; Banerjee, S.; Vanka, K.; Banerjee, R. A Porous Porphyrin Organic Polymer (PPOP) for Visible Light Triggered Hydrogen Poduction. Chem. Commun. 2017, 53, 4461-4464.

(60) Li, X.; Li, K.; Wang, D.; Huang, J.; Zhang, C.; Du, Y.; Yang, P. One-pot synthesis of Manganese porphyrin Covalently Functionalized Graphene Oxide for Enhanced Photocatalytic Hydrogen Evolution. J. Porphyrins Phthalocyanines 2017, 21, 179-188. 